\title{
SLC29A1 single nucleotide polymorphisms as independent prognostic predictors for survival of patients with acute myeloid leukemia: an in vitro study
}

Haixia Wan $^{\dagger}$, Jianyi Zhu ${ }^{\dagger}$, Fangyuan Chen ${ }^{*}$, Fei Xiao, Honghui Huang, Xiaofeng Han, Lu Zhong, Hua Zhong, Lan Xu, Beiwen $\mathrm{Ni}$ and Jihua Zhong

\begin{abstract}
Background: The mechanism behind poor survival of acute myeloid leukemia (AML) patients with 1-barabinofuranosylcytosine (Ara-C) based treatment remains unclear. This study aimed to assess the pharmacogenomic effects of Ara-C metabolic pathway in patients with AML.

Methods: The genotypes of 19 single nucleotide polymorphisms (SNPs) of DCK, CDA and SLC29A1from 100 AML patients treated with Ara-C were examined. All the SNPs were screened with ligase detection reaction assay. The transcription analysis of genes was examined by quantitative real time polymerase chain reaction. The association between clinical outcome and gene variants was evaluated by Kaplan-Meier method.

Results: Genotypes of rs9394992 and rs324148 for SLC29A1 in remission patients were significantly different from those in relapsed ones. Post-induction overall survival (OS) significantly decreased in patients with the CC genotype of rs324148 compared with CT and TT genotypes (hazard ratio [HR] = 2.997 [95\% confidence interval (Cl): 1.71-5.27]). As compared with $C T$ and $T$ genotype, patients with the CC genotype of rs9394992 had longer survival time ( $H R=0.25$ [95\% Cl: $0.075-0.81] ; \mathrm{HR}=0.43$ [95\% Cl: 0.24-0.78]) and longer disease-free survival (DFS) (HR $=0.52$ [95\% Cl: 0.29-0.93]; $\mathrm{HR}=0.15$ [95\% Cl: 0.05-0.47]) as well As compared with CT and TT genotype, patients with the CC genotype of rs324148 had shorter DFS (HR = 3.18 [95\% Cl: 1.76-5.76]). Additionally, patients with adverse karyotypes had shorter DFS ( $\mathrm{HR}=0.17$ [95\% Cl: 0.05-0.54]) and OS ( $\mathrm{HR}=0.18$ [95\% Cl: 0.05-0.68]).
\end{abstract}

Conclusions: AML patients with low activity of SLC29A1 genotype have shorter DFS and OS in Ara-C based therapy. Genotypes of rs9394992 and rs324148 may be independent prognostic predictors for the survival of AML patients.

Keywords: AML, SNP, Ara-C, Genotype

\section{Background}

Acute myeloid leukemia (AML), a heterogeneous disease with various clinical presentations, can be treated with 1-barabinofuranosylcytosine (Ara-C) or Ara-C combined with anthrocycline [1-3]. Despite the big progress in respect to the improved remission rate of a majority of patients (50-60\%) under 60 years old, the outcome of Ara-C based treatment is still unsatisfactory as $30-80 \%$

\footnotetext{
*Correspondence: chenfangyuan62@163.com

${ }^{\dagger}$ Equal contributors

Department of Hematology, Ren Ji Hospital, School of Medicine, Shanghai Jiao Tong University, 160 Pujian Road, Shanghai 200127, China
}

of patients relapse eventually after remission [4]. Besides, long-term survival rates continue to be around $30 \%$ to $40 \%$ for adults, and treatment of patients with relapsed or refractory AML with Ara-C based chemotherapy is unable to produce a prolonged leukemiafree survival in most patients $[4,5]$. The mechanism behind poor survival of AML patients with Ara-C based treatment still remains unclear.

The cytotoxic effect of Ara-C needs metabolic activation following transport into the cells. When administered in standard doses, Ara-C is transported into cells via membrane transporters including the solute carrier family 29

\section{Ciomed Central}

(c) 2014 Wan et al.; licensee BioMed Central Ltd. This is an Open Access article distributed under the terms of the Creative Commons Attribution License (http://creativecommons.org/licenses/by/4.0), which permits unrestricted use, distribution, and reproduction in any medium, provided the original work is properly credited. The Creative Commons Public Domain Dedication waiver (http://creativecommons.org/publicdomain/zero/1.0/) applies to the data made available in this article, unless otherwise stated. 
(nucleoside transporters) member 1 (SLC29A1) [6,7]. High-dose Ara-C diffuses into the cell at a rate higher than that of pump-mediated transport [6,7]. Inside the cell, Ara-C is converted to its active triphosphate form (Ara-CTP) through a series of phosphorylation actions mediated by deoxycytidine kinase (DCK), deoxycytidylate kinase and nucleoside diphosphate kinase (NDPK) [8,9] (Figure 1). DCK is the rate-limiting enzyme in this process. Ara-CTP plays its cytotoxic role by incorporating into DNA to inhibit DNA synthesis in a competitive way, resulting in leukemic cell death [10-13]. Cytoplasmic 5'-nucleotidase (5-NT) dephosphorylates Ara-CMP, a key intermediate, to prevent accumulation of Ara-CTP, which might reduce cellular sensitivity to the cytotoxic activity of Ara-C [14]. CDA can catalyze the hydrolytic deamination of Ara-C to its inactive metabolite 1-B-Darabinofuranosyluracil (Ara-U). Ribonucleotide reductase (RRM), which consists of 2 subunits, could decrease Ara-C cytotoxycity by catalyzing the de novo synthesis of dNTP which could inhibit the function of DCK [15-18].

Genes involved in Ara-C transport and metabolism, and the potential mechanisms of Ara- $\mathrm{C}$ resistance, are investigated in the previous studies. DCK can be inhibited by increased dCTP pool through a negative feedback, and increased CDA function leads to increase in the deamination of Ara-C to AraU [19-21]. Decreased Ara-C transport over the cell membrane into the cytoplasm $[6,22]$ or inactivation of DCK $[23,24]$ can both offset the cytotoxic function of Ara-C. Our previous study showed continuous exposure to Ara- $\mathrm{C}$ could induce drug resistance with decreased transcription level of DCK and SLC29A1 as well as elevated mRNA expression of CDA (data not shown). Genetic variations, particularly SNPs, have been identified in these genes involved in Ara-C transport and metabolism [25-27]. Both in vivo and in vitro studies demonstrated that the activities of these enzymes are correlated with polymorphic gene variations [28,29], and some of these SNPs

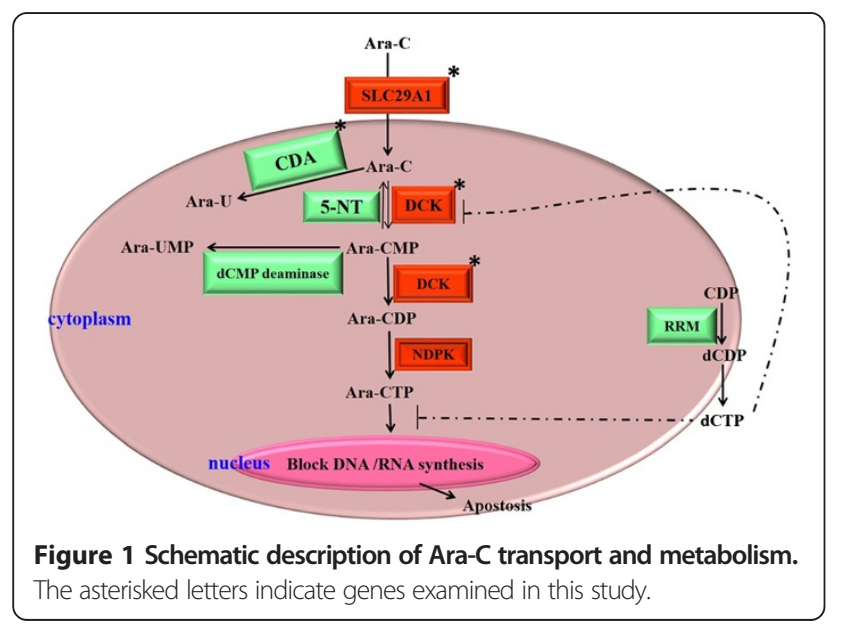

are even highly correlated with treatment response and survival of AML patients with Ara-C based chemotherapy [30-33]. Previous study found that rs329491 of SLC29A1 maybe a favorable survival factor for patients with pancreatic cancer [34]. Another study also showed that rs9394992 may be associated with the survival of patients with non-small cell lung cancer [35]. However, none of these SNPs have been reported in leukemia patients.

To investigate the possible involvement of genes correlating with Ara-C transport and metabolism in patients with chemotherapy-resistant AML, we assessed the pharmacogenomic effects of Ara-C metabolic/transport pathway in AML in this study.

\section{Results}

Patients' characteristics and treatment outcomes

Baseline characteristics and treatment results of the 100 AML patients were summarized in Table 1. A total of 51 patients $(54.8 \%)$ were of normal karyotype. Among the patients who were available for their cytogenetic or molecular information, 14 patients had $t(8 ; 21)$ (q22; q22). Of the 93 patients detected, 8 patients carried NPM1 mutation, and 5 patients with FLT3 internal tandem duplication (ITD) mutation were identified in 92 patients. The median and mean follow-up duration were 44 and 37.8 months, respectively. $74 \%(\mathrm{n}=74)$ of patients achieved remission after one cycle $(n=69)$ or two cycles $(n=5)$ of Ara-C based induction chemotherapy. Overall,

Table 1 Characteristics of AML patients

\begin{tabular}{|c|c|c|c|c|}
\hline Characteristics & $\sum n$ & $n$ & $\%$ & Median (range) \\
\hline Gender (Male/female) & 100 & $42 / 58$ & $42 / 58$ & \\
\hline Age (years) & 100 & & & $43(17-76)$ \\
\hline Bone marrow blasts (\%) & 92 & & & $67.3(37.5-97)$ \\
\hline WBC count $\left(\times 10^{9} / \mathrm{L}\right)$ & 95 & & & $17.9(2.5-193.9)$ \\
\hline FAB classification & 100 & & & \\
\hline M2 & & 10 & 10 & \\
\hline M4 & & 48 & 48 & \\
\hline M5 & & 40 & 40 & \\
\hline M6 & & 2 & 2 & \\
\hline Karyotype & 93 & $51 / 42$ & $54.8 / 45.2$ & \\
\hline \multicolumn{5}{|l|}{ Normal/abnormal } \\
\hline Favorable & & 20 & 21.5 & \\
\hline Intermediate & & 65 & 69.9 & \\
\hline Adverse & & 8 & 8.6 & \\
\hline NPM1 & 93 & $8 / 85$ & $8.6 / 91.4$ & \\
\hline \multicolumn{5}{|l|}{ Positive/negative } \\
\hline FLT-ITD & 92 & $5 / 87$ & $5.4 / 94.6$ & \\
\hline Positive/negative & & & & \\
\hline
\end{tabular}

$\mathrm{FAB}$, French-American-British. 
the five-year DFS and OS rate of the AML patients was $(35.7 \pm 2.4) \%$, and $(43.2 \pm 2.2) \%$, respectively.

\section{Transcription level of genes involving in Ara-C transport and metabolism}

To detect the transcription of DCK, CDA and SLC29A1, we examined mRNA expression of these genes in the leukemia blasts from the bone marrow of AML patients. The results showed that the RNA expression of DCK and SLC27A1in patients with complete remission was higher than that of non-remission ones, while CDA expression in the remission patients was lower than that of non-remission ones (Figure 2). The similar results was identified in our previous in-vitro study as well (Additional file 1c).

\section{Genotype frequencies of DCK, CDA and SLC29A1 polymorphisms}

19 SNPs (Table 2) of DCK, CDA and SLC29A1 were screened in 100 AML patients and 100 healthy controls, and their genotype frequencies and allele frequencies were summarized (Additional file 2). SNP15 was excluded from analysis since only one genotype was identified in the AML patients and normal healthy controls. Genotype frequencies of the other 18 SNPs were identified in Hardy-Weinberg equilibrium $\left(\chi^{2}=0.002-3.590\right.$, $\mathrm{P}=0.580-0.960$ ). No difference of genotype and allele frequencies of all the 18 SNPs were found between the AML patients and the healthy controls. Genotype frequencies were not significantly different between male and female AML patients. No significant correlation was observed between other AML prognostic factors including WBC at presentation, age or cytogenetic abnormalities, and genotypes of SLC29A1 polymorphic variants. The two SNPs of SLC29A1b, rs324148 and rs9394992, were not in strong linkage disequilibrium (LD) ( $\left.\mathrm{D}^{\prime}=0.73, \mathrm{r}^{2}=0.11\right)$ in $\mathrm{CHB}$ as well as $\mathrm{LD}$ and $\operatorname{CEU}\left(D^{\prime}=0.38, r^{2}=0.03\right.$ ) (Figure 3a, b).

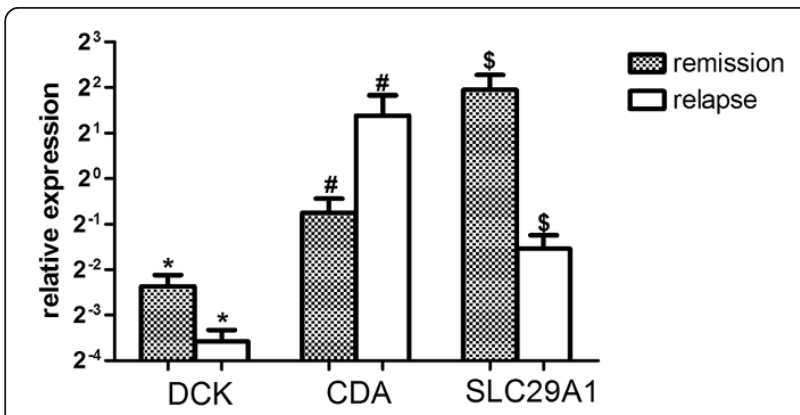

Figure 2 The mRNA expression of genes related to Ara-C efficacy in AML. Gene expression levels of DCK, CDA, and SLC29A1 were analyzed by quantitative RT-PCR. $\beta$-actin was used as an internal control. ${ }^{*} \$$ indicated statistically significant $(P<0.05)$.
Impact of SNP genotypes on treatment response

To identify the correlation between genotypes of SNPs with Ara-C based treatment response, all 19 SNPs were screened. The results showed that genotype frequency of genotype CC in SNP16 was higher in relapsed patients, while frequencies of $\mathrm{CT}$ and TT were higher in remission ones $(\mathrm{P}=0.04)$. For SNP18, more genotype frequency of genotype $\mathrm{CC}$ was found in remission patients, while higher frequencies of genotype $\mathrm{CT}$ and TT were found in relapsed ones $(P=0.0004)$ (Figure $4 a, b)$.

\section{Impact of genotypes of rs9394992 and rs324148 on SLC29A1 transcription}

To further investigate the effect of different genotypes of polymorphic varies on the transcription of SLC29A1, we evaluated the mRNA expression of the rs9394992 and rs324148 of SLC29A1 in AML patients. Higher mRNA expression of genotype TT was observed in rs324148, as compared to that of genotype CC $(\mathrm{P}<0.01)$. Higher expression of genotype CC was observed in rs9394992 compared with genotype $\mathrm{CT}$ and TT $(\mathrm{P}<0.01)$ (Figure $4 \mathrm{c})$, which indicated that SNPs might modify Ara-C toxicity through transcription regulation.

\section{The effect of SNPs on Ara-C based treatment outcomes}

Univariate analysis found that SNP18 (rs9394992) and SNP16 (rs324148) of SLC29A1, were significant prognostic factors to OS and DFS (Figure 5). The CC genotype of SNP16 was significantly associated with shorter overall survival time compared to the CT and TT genotypes (hazard ratio $[\mathrm{HR}]=2.997$ [95\% confidence interval (CI): 1.71-5.27], $\mathrm{P}=0.0001$ ) (Figure 5a). The genotype of $\mathrm{CC}$ in SNP18 was significantly associated with longer survival time compared to $\mathrm{CT}$ ( $\mathrm{HR}=0.25$ [95\% CI: 0.0750.81 ], $\mathrm{P}=0.02)$ or TT genotypes ( $\mathrm{HR}=0.43$ [95\% CI: 0.24 0.78 ], $\mathrm{P}=0.005$ ) (Figure 5c). This association was more significant in patients with both genotype CC of rs324148 and genotype CT + TT of rs9394992 (Figure 6a).

The CC genotype of SNP16 was significantly associated with shorter DFS compared to the CT and TT genotypes $(\mathrm{HR}=3.18$ [95\% CI: $1.76-5.76], \mathrm{P}=0.0001)$ (Figure $5 \mathrm{~b})$. Genotype of CC of SNP18 was associated with longer DFS compared to CT (HR $=0.52$ [95\% CI: 0.29-0.93], $\mathrm{P}=0.03)$ or TT genotypes $(\mathrm{HR}=0.15$ [95\% CI: 0.05- 0.47], $\mathrm{P}=0.001$ ) (Figure $5 \mathrm{~d}$ ). This association was more significant in patients with both genotype CC of rs324148 and genotype CT + TT of rs9394992 (Figure 6b).

\section{Impact of other variables on Ara-C based treatment outcomes}

No effects of age, gender and FAB subtypes on the DFS and OS of AML patients were identified (Additional file 3), whereas adverse cytogenetic abnormalities indicated poorer prognosis. However, no difference of DFS and OS was 
Table 2 Characteristics of 19 SNPs

\begin{tabular}{|c|c|c|c|c|c|c|}
\hline Gene & SNP & HGVS Names & ref SNP ID & Global MAF & Location & Chromosome position \\
\hline \multirow[t]{7}{*}{ DCK } & SNP1 & NM_000788.2:C.-201C > T & rs2306744 & $0.060 / 130$ & exon & $4: 71859352$ \\
\hline & SNP2 & NM_000788.2:C.207 + 9846A > G & rs12648166 & $0.458 / 998$ & intron & $4: 71873745$ \\
\hline & SNP3 & NM_000788.2:C.757-1205C > T & rs4694362 & $0.467 / 1015$ & intron & $4: 71893864$ \\
\hline & SNP4 & NM_000788.2:c.165C > T & rs4643786 & $0.227 / 494$ & exon & $4: 71895260$ \\
\hline & SNP5 & NM_000788.2:c.207 + 11338A > G & rs7684954 & $0.197 / 430$ & intron & $4: 71875237$ \\
\hline & SNP6 & NM_000788.2:c.666-346 T > C & rs936869 & $0.196 / 426$ & intron & $4: 71892036$ \\
\hline & SNP7 & NM_000788.2:C.92-1110 T >C & rs3775289 & $0.193 / 419$ & intron & $4: 71862674$ \\
\hline \multirow[t]{8}{*}{ CDA } & SNP8 & NM_000788.2:C.266 + 3264A > G & rs1689924 & $0.482 / 1049$ & intron & $1: 20934796$ \\
\hline & SNP9 & NM_000788.2:C.267-4159C > T & rs572529 & $0.350 / 761$ & intron & $1: 20936176$ \\
\hline & SNP10 & NM_000788.2:c.267-4087G > A & rs477155 & $0.279 / 606$ & intron & $1: 20936248$ \\
\hline & SNP11 & NM_000788.2:C.154 + 1015A > G & rs818202 & $0.480 / 1045$ & intron & $1: 20916791$ \\
\hline & SNP12 & NM_000788.2:c.155-7161G > A & rs818199 & $0.386 / 840$ & intron & $1: 20924260$ \\
\hline & SNP13 & NM_000788.2:C.266 + 1809G > A & rs10916827 & $0.345 / 752$ & intron & $1: 20933341$ \\
\hline & SNP14 & NM_000788.2:C.266 + 2751G > A & rs527912 & $0.349 / 759$ & intron & $1: 20934283$ \\
\hline & SNP15 & NM_000788.2:C.208G > A & rs60369023 & $0.002 / 4$ & exon & $1: 20931474$ \\
\hline \multirow[t]{4}{*}{ SLC29A1 } & SNP16 & NM_001078174.1:C.30-549 T > C & rs324148 & $0.228 / 496$ & intron & $6: 44196578$ \\
\hline & SNP17 & NM_001078174.1:c.1260-201A > G & rs760370 & $0.344 / 750$ & intron & $6: 44200953$ \\
\hline & SNP18 & NM_001078174.1:c.29 + 913C>T & rs9394992 & $0.290 / 631$ & intron & 6:44195992 \\
\hline & SNP19 & NM_001078174.1:c.-54-3077A > G & rs693955 & $0.189 / 411$ & intron & $6: 44191920$ \\
\hline
\end{tabular}

SNP, single-nucleotide polymorphism; rfID., reference SNP identification; HGVS Names, Human Genome Variation Societyname; MAF, minor allele frequency.

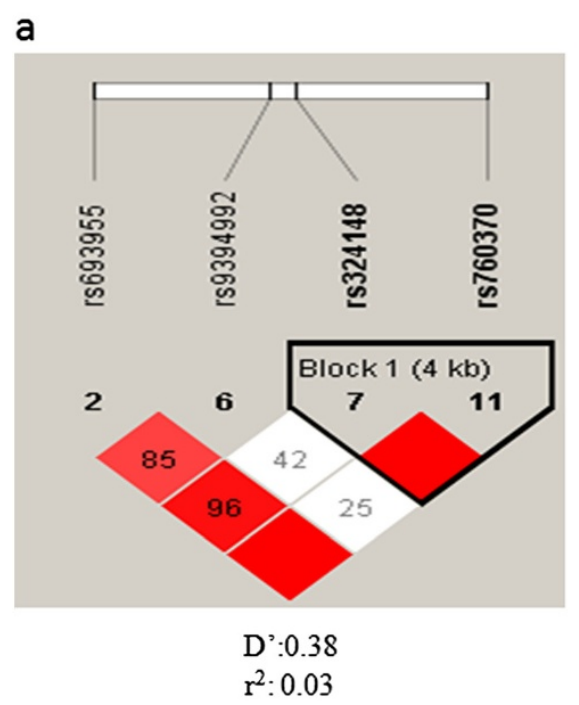

SLC29A1-CEU b

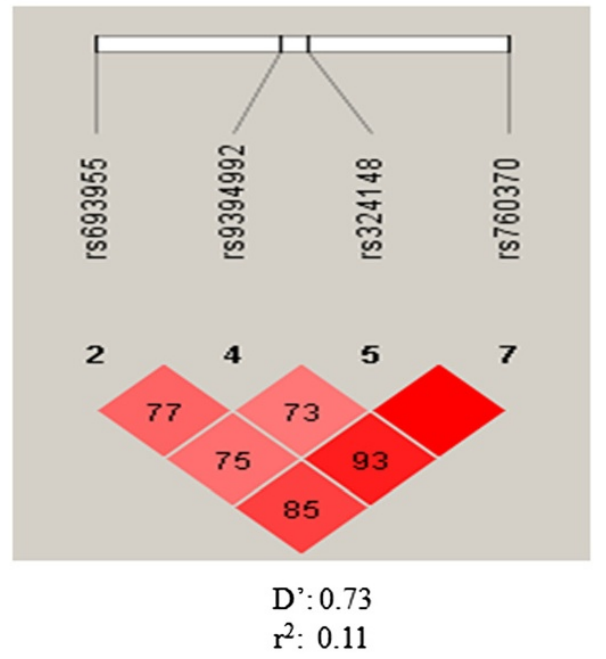

SLC29A1-CHB

Figure 3 SLC29A1 Haplotype structure. The haplotype structure of SLC29A1 was generated based on HapMap Phase II + III Release 27 data. Colors ranging from bright red to light red to white indicate the range of $r 2$ values from high to low. The link of rs9394992 to rs324148 that we identified in the survival analysis for AML patients is in the white (a) or light red box (b) with $r 2<0.5$. CHB: Han Chinese in Beijing, China. CEU: Utah residents with Northern and Western European ancestry from CEPH collection. 
a $\quad$ rs324148 (remission vs. relapse: $\mathrm{P}=0.04$ )
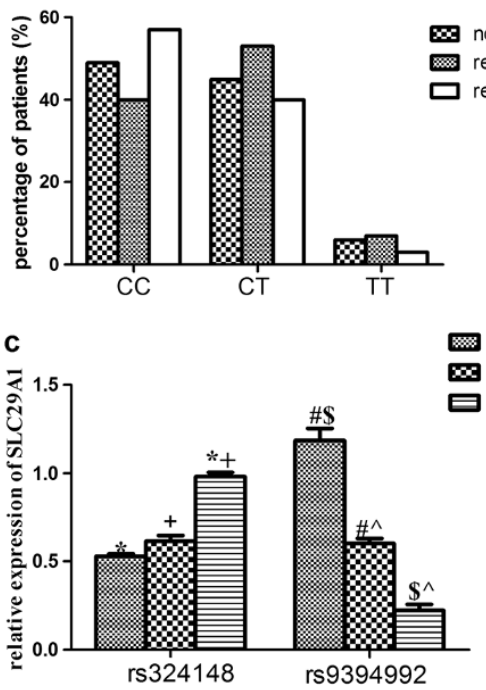

b rs9394992 (remission vs, relapse: $\mathrm{P}=0.0004$ )

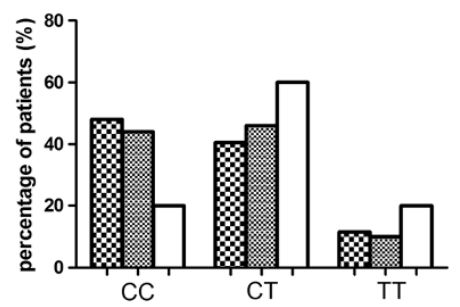

$\infty$ normal

remission

$\square$ relapse

Figure 4 Genotype frequencies of SNP16 (rs324148) and SNP18 (rs9394992) in AML patients and healthy control, and their impact on the mRNA expression of SLC29A1. a, genotype frequencies of SNP16 (rs324148) in remission and relapsed patients, and in healthy control. Frequency of genotype CC was higher in relapsed patients than those of CT and $\Pi(P=0.04)$; $\mathbf{b}$, genotype frequencies of SNP18 (rs9394992) in remission and relapsed patients, and in healthy control. Frequencies of genotype CT and $T T$ were higher in relapsed patients than those of CC $(P=0.0004)$. No difference of genotype frequencies of both SNPs was observed between healthy control and remission patients. $\mathbf{c}$, relative mRNA expression of SLC29A1 in patients with different genotypes of SNP16 and SNP18 by quantitative real time PCR, $\beta$-actin was used as an internal control. *\#+\$^ indicated statistically significant $(P<0.05)$.

observed between intermediate and favorable cytogenetic abnormalities (Figure 7).

\section{Discussion}

It has been demonstrated in the previous studies that cytogenetics and molecular abnormalities were independent predictors for the prognosis of AML patients [36-38]. However, in our study, adverse cytogenetic abnormalities only accounted for $8.6 \%(\mathrm{n}=93)$ of patients. The majority of patients was with intermediate and favorable cytogenetics and showed no difference in survival. As Ara-C forms the backbone of the treatment regimen, understanding the a

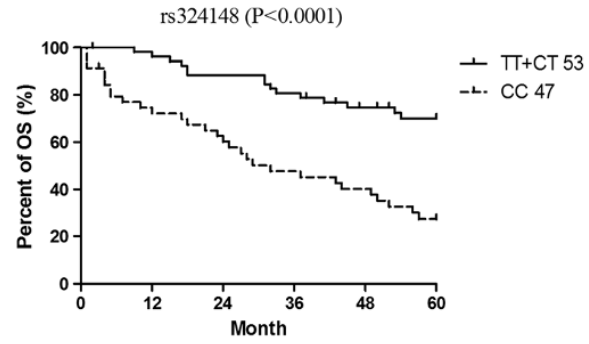

C

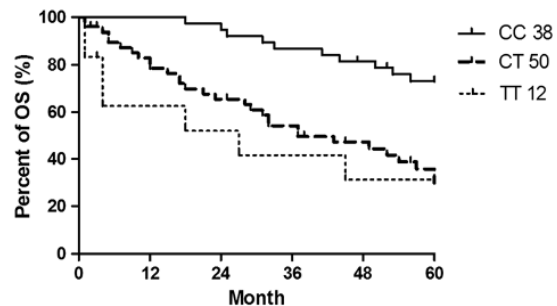

b

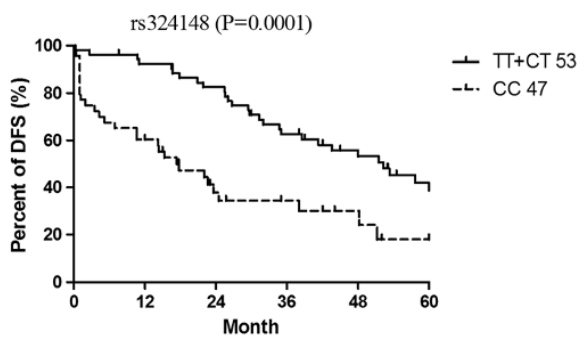

d

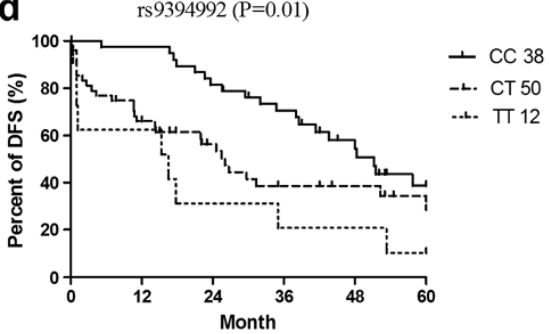

Figure 5 Univariate analysis of survival rates based on genotypes of SNP16 (rs324148) and SNP19 (rs9394992). a: effect of SNP16 on OS of AML, $\mathbf{b}$ : effect of SNP16 on DFS of AML; $\mathbf{c}$, effect of SNP18 on OS of AML; $\mathbf{d}$, effect of SNP18 on DFS of AML. 

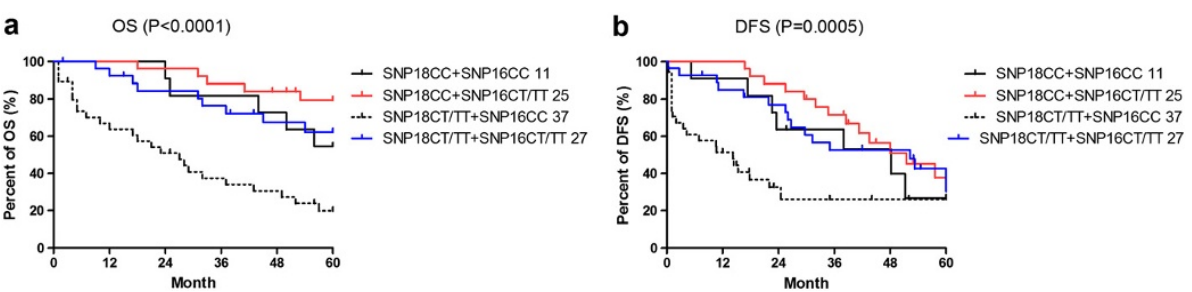

Figure 6 Effect of SNP-SNP interactions on OS and DFS of patients with AML. a, combined effects of SNP16 and SNP18 on OS of patients with AML; $\mathbf{b}$, combined effects of SNP16 and SNP18 on DFS of patients with AML.

contribution of pharmacogenetics to Ara-C response may help dissection of AML with distinct prognosis, so as to individualize chemotherapy and potentially improve the outcomes of AML patients.

In our study, we observed single SNP and SNP-SNP interactions in the Ara-C transport pathway, which could account for the interpatient variability of treatment outcomes in AML patients. When tested independently, both SNP rs324148 and rs9394992 in the SLC29A1gene contributed to Ara-C resistance in patients with AML who received Ara-C based treatment, and they were also significant prognostic factors for survival of these patients. The genotypes of these two SNPs showed various mRNA expressions, which may be responsible for varied response to Ara-C treatment. Although the SNPs in our study located in the intron region of SLC29A1, they affected mRNA expression, which might be due to direct regulation of transcription by altering RNA elongation, splicing or maturation [39-41].

SLC29A1 was expressed in $83 \%$ of the AML patients [6]. The results of the studies on the association between SLC29A1 of human AML blasts and clinical drug response were not consistent. Previous data showed that there was no association between SLC29A1 and Ara-C sensitivity [42]. However, some studies demonstrated close correlation of SLC29A1 with Ara-C resistance, treatment response and survival of patients with AML. The inhibition of SLC29A1 expression may induce Ara-C resistance; thereby reduce the overall survival of patients with AML $[6,43]$. FLT3-ITD indicates poor prognosis in AML, and one of the mechanisms involved was to suppress the expression of SLC29A1 to induce Ara-C resistance in AML patients [44].

Besides SLC29A1, other genes or mechanisms may be responsible for Ara-C resistance. Previous in-vitro studies showed that the expression of DCK was correlated with cellular sensitivity to Ara-C, while decreased DCK activity was observed in Ara-C resistant cell lines $[24,45,46]$. DCK and 5-NT mRNA expression in leukaemic blasts at diagnosis was correlated with clinical outcome [47], although no alterations in DCK expression and/or activity were observed in resistant and sensitive AML patients [48]. Alternatively spliced forms of DCK with reduced activity were found in Ara-C resistant blasts $[48,49]$, suggesting that DCK may contribute to Ara-C resistance. Our study detected higher DCK expression in leukemia blast in remission patients, but failed to find any difference of polymorphisms between remission and relapsed patients. CDA may be another factor for Ara-C resistance. Elevated CDA activity was correlated with Ara-C resistance [33,50]. CDA could be an independent prognostic parameter for survival in AML patients treated with Ara-C [27]. Other genes, including 5-NT and RRM1 or RRM2, were also found to be involved in Ara-C resistance $[14,26,47,51,52]$.

Our study failed to detect the activity of SLC29A1A in AML patients, in whom we inferred SLC29A1 activity from genotype or mRNA expression correlated with Ara-C sensitivity [43]. In addition, we could not differentiate
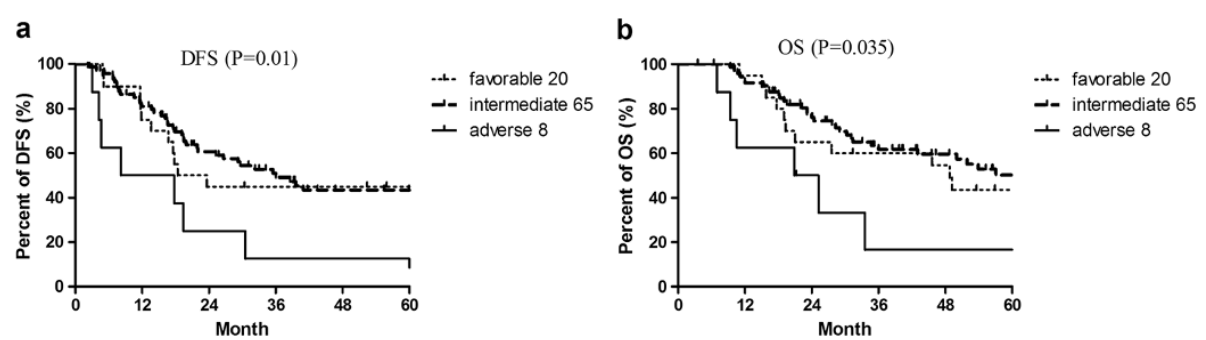

Figure 7 Univariate analysis of cytogenetic abnormalities on DFS and OS of patients with AML. Effect of cytogenetic abnormalities on OS and DFS. $\mathbf{a}$, Effects of cytogenetic abnormalities on DFS; $\mathbf{b}$, Effects of cytogenetic abnormalities on OS. Risk status was evaluated according to the NCCN guidelines version 2.2014 for AML (https://www.ncen.org). 
the difference of survival between different genotype combinations of rs9394992 and rs324148, which might be due to other SNPs. Studies showed DCK rs4694362 (CC genotype) may be a poor prognostic factor for the OS of AML patients. SLC29A1 rs3734703 (AA or AC genotype) together with TYMS rs2612100 (AA genotype) were associated with shorter relapse free survival (RFS) [31]. Polymorphisms within the CDD gene also had an impact on the survival of patients with AML [27]. In AML patients without FLT3-ITD, variant allele of rs10883841 in 5-NT was associated with shorter survival [26]. In addition, polymorphisms of other genes were also identified to be responsible for the prognosis of AML patients [53,54]. Therefore, more parameters need to be included for better prognostic stratification.

Interestingly, our previous study found that fludarabine (Flu) may restore the Ara-C sensitivity in AML blasts (Additional file 1a,b) and increase the cytoxicity of Ara-C (Additional file 1a), partially by increasing the mRNA expression of DCK, SLC29A1, and decreasing mRNA expression of CDA, RRM1 and RRM2 (Additional file 1c). Clinical studies also suggested that Flu may have a beneficial impact on the antileukemic efficacy of Ara-C-based salvage therapy for relapsed and refractory AML $[55,56]$.

In conclusion, cytogenetics might not be enough to predict the prognosis of AML. Polymorphisms in genes related to its Ara-C metabolism may serve as biomarkers for Ara- $\mathrm{C}$ sensitivity, treatment response, and prognostic markers in AML, thus individualize chemotherapy and potentially improve outcomes of AML patients.

\section{Materials and methods Patients}

From July 2004 to July 2009, 100 Asian Chinese adults with de novo AML other than M3 were randomized to receive low-dose cytarabine $\left(100 \mathrm{mg} / \mathrm{m}^{2}\right.$ intravenously for 24 hours, given on day $1-7 ; \mathrm{n}=100$ ) plus daunorubicin $\left(45 \mathrm{mg} / \mathrm{m}^{2}\right.$ intravenously on day $\left.1-3\right)$ or indarubicin $\left(10 \mathrm{mg} / \mathrm{m}^{2}\right.$ intravenously on day $\left.1-3\right)$. High-dose cytarabine $\left(2 \mathrm{~g} / \mathrm{m}^{2}\right.$ intravenously over 3 hours, given every 12 hours on day $1-3 ; n=27$ ) was administered to patients for second cycle induction $(n=4)$ or for consolidation. All patients were chemonaive at enrollment with leukemia blasts $>70 \%$ in the bone marrow. Meanwhile, 100 healthy controls (media age: 46 years, range 14-84 years; $n=50$ for male) were also included.

Subjects diagnosed with any other cancers or perniciously administered cytotoxic drugs or radiation was excluded. Primary bone marrow samples were collected after informed consent was obtained from patients or their guardians, in accordance with the Declaration of Helsinki. This study was approved by the institutional research board at Renji Hospital, Shanghai.

\section{SNP selection and genotyping}

Three cytarabine transport and metabolism genes including SLC29A1, DCK and CDA were reported to potentially involve in the response to cytarabine. Based on the database from NCBI (http://www.ncbi.nlm.nih.gov/) and International Hap-Map project (http://hapmap.ncbi. nlm.nih.gov/), 19 candidate SNPs in these genes were initially selected.

Mononuclear cells (MNCs) were purified with Ficoll. Genomic DNA was extracted from MNC samples using standard methods recommended and normalized to $1 \mu \mathrm{g} / \mu \mathrm{l}$. Quality and quantity of the extracted DNA was checked on a Nanodrop ND-1000 UV-vis Spectrophotometer (NanoDrop Technologies, Wilmington, DE, USA) by spectral absorption scans from 230 to $350 \mathrm{~nm}$. Genotyping for the all genes' polymorphism was performed using ligase detection reaction (LDR) assay following the manufacturer's instructions. Genespecific polymerase chain reaction (PCR) primers and fluorogenic probes for allelic discrimination were supplied by Shanghai Generay Biotech. PCR cycling and ligation reactions were performed in a GeneAmp PCR System 9700 (Applied Biosystems, Foster City, CA) according to the conditions specified by the manufacturer. Ligation products were analyzed using ABI PRISM ${ }^{\circledR} 377$ DNA Sequencer (Applied Biosystems, Foster City, CA). Genotyping results were duplicated in $15 \%$ of samples with $100 \%$ concordance between repeats.

Genomic DNA was extracted from peripheral blood samples of 100 healthy donors using QIAamp blood DNA isolation kits (Qiagen Sciences, Maryland, USA) as per the manufacturer's protocol. Genotyping was performed as described for the patient population.

\section{Real time PCR}

$0.5 \times 10^{6}$ leukemia cells were harvested, and total RNA was extracted using the RNeasy Plus Mini kit (QIAGEN, $\mathrm{GmbH}$, Hilden, Germany) following the manufacturer's protocol. RNA quality and quantification were assessed using the optical spectrometry $260 / 280 \mathrm{~nm}$ ratio. Subsequently, mRNA was reverse transcribed to cDNA using Applied Biosystems High Capacity Reverse Transcription kit (Applied Biosystems, Foster City, CA). Quantitative RT-PCR was performed for DCK, CDA and SLC, with $\beta$-actin as the internal control, using SYBR Premix Ex Taqs (TaKaRa, Kyoto, Japan) on the Roche LightCycler ${ }^{\circ}$ 480 system (Roche, Mannheim, Germany). Total reaction was carried out in $10 \mu \mathrm{L}$ volume, which consisted of $5 \mu \mathrm{L}$ SYBR Premix Ex Taqs Master Mix, $0.1 \mu \mathrm{L}$ primers (final of $10 \mathrm{nM}$ forward and reverse primers), and $4 \mu \mathrm{L}$ water, along with $0.8 \mu \mathrm{L}$ cDNA. The fast thermocycler parameters were: $95^{\circ} \mathrm{C}$ for 10 seconds, and 40 cycles of $95^{\circ} \mathrm{C}$ for 5 second then $60^{\circ} \mathrm{C}$ for 30 seconds and $78^{\circ} \mathrm{C}$ for 1 second. The qRT-PCR was run in triplicate and individual samples 
run in triplicate on the RT-PCR plates. Primers were supplied by Sangon Biotech in shanghai.

\section{Definitions}

Disease-free survival (DFS) was defined as time from remission to failure at the end of two courses, relapse or death of any cause. Overall survival (OS) was defined as time from study entry to death of any cause. Complete remission (CR) after induction chemotherapy was defined as: (1) normal values for absolute neutrophil $(>1000 / \mathrm{mcL})$ and platelet counts $(\geq 100,000 / \mathrm{mcL})$ independent of transfusion; (2) less than $5 \%$ of blast cells, no blasts with Auer rods on bone marrow examination; (3) absence of extramedullary leukemia. Partial remission (PR) was defined as decrease of at least $50 \%$ in the percentage of blasts to $5-25 \%$ in the bone marrow aspirate and the normalization of blood counts. $\mathrm{CR}$ and PR were defined as overall remission. Relapse was defined as marrow infiltration by more than $5 \%$ of blast cells in previous normal bone marrow or evidence of extramedullary leukemia. Patients lost to follow-up, survived (for OS) or maintained remission (for DFS) up to the end of the research were censored at their date of last known contact.

\section{Statistical analysis}

Differences of the frequencies between genotypes and alleles in AML (remission and relapsed) patients and normal controls were evaluated using Chi-square test and Fisher's exact test when data were sparse. The expression of mRNA between different genotypes of SNPs or between different genes was analyzed with $t$ test. DFS and OS were calculated using Kaplan-Meier estimates. A cut off P-value of 0.05 was adopted for all statistical analyses. Statistical significance is represented by the two-tailed $P$ values.

\section{Additional files}

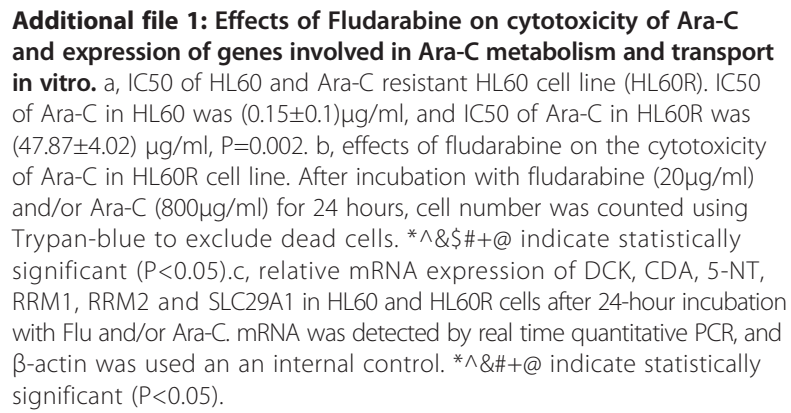

Additional file 2: Genotype/allele frequencies of 19 SNPs of DCK, CDA and SLC29A1 in healthy control and AML patients. $a, b, c$ showed genotype frequencies of 19 SNPs of DCK, CDA and SLC29A1; $d, e, f$ showed allele frequencies of 19 SNPs of DCK, CDA and SLC29A1. No significant difference of genotype/allele frequencies was observed between the AML patients and healthy controls. Genotype frequencies of the 18 SNPS except SNP15 (only one genotype in AML patients and normal donors) were found to be in Hardy-Weinberg equilibrium ( $\left.X^{2}=0.002-3.590, P=0.580-0.960\right)$.

Additional file 3: Univariate analysis of gender, age, FAB classification on DFS and OS of patients with AML. a, Effect of age on OS and DFS; $b$, effect of gender on OS and DFS; $c$, effect of FAB classification on OS and DFS.

\section{Competing interests}

The authors declare that they have no competing interests.

\section{Authors' contributions}

HW performed the research, analyzed the data, and wrote the manuscript; FC designed and supervised the research; JZ, FX and HH collected clinical samples and data; JZ was responsible for part of the experiment. All authors read and approved the final manuscript.

\section{Acknowledgments}

The authors appreciated the contribution from the members of Leukemia Research Institute in Ren Ji Hospital. The study was partially supported by Science and Technology Commission of Shanghai Municipality

(no.14411950704), Shanghai Jiaotong University as well as the Science and Technology Research Fund (2008XJ015).

Received: 2 September 2014 Accepted: 20 October 2014

Published online: 15 November 2014

\section{References}

1. Harousseau JL, Reiffers J, Hurteloup P, Milpied N, Guy H, Rigal-Huguet F, Facon $T$, Dufour $P$, Ifrah $N$ : Treatment of relapsed acute myeloid leukemia with idarubicin and intermediate-dose cytarabine. J Clin Oncol 1989, 7:45-49.

2. Nazha A, Kantarjian H, Ravandi F, Huang X, Choi S, Garcia-Manero G, Jabbour E, Borthakur G, Kadia T, Konopleva M, Cortes J, Ferrajoli A, Kornblau S, Daver N, Pemmaraju N, Andreeff M, Estrov Z, Du M, Brandt M, Faderl S: Clofarabine, idarubicin, and cytarabine $(\mathrm{CIA})$ as frontline therapy for patients $</=60$ years with newly diagnosed acute myeloid leukemia. Am J Hematol 2013, 88:961-966.

3. Willemze R, Suciu S, Meloni G, Labar B, Marie JP, Halkes CJ, Muus P, Mistrik M, Amadori S, Specchia G, Fabbiano F, Nobile F, Sborgia M, Camera A, Selleslag DL, Lefrère F Sr, Magro D, Sica S, Cantore N, Beksac M, Berneman Z, Thomas X, Melillo L, Guimaraes JE, Leoni P, Luppi M, Mitra ME, Bron D, Fillet G, Marijt EW, et al: High-dose cytarabine in induction treatment improves the outcome of adult patients younger than age 46 years with acute myeloid leukemia: results of the EORTC-GIMEMA AML-12 trial. J Clin Oncol 2014, 32:219-228.

4. Norsworthy K, Luznik L, Gojo I: New treatment approaches in acute myeloid leukemia: review of recent clinical studies. Rev Recent Clin Trials 2012, 7:224-237

5. Tallman MS, Gilliland DG, Rowe JM: Drug therapy for acute myeloid leukemia. Blood 2005, 106:1154-1163.

6. Galmarini CM, Thomas X, Calvo F, Rousselot P, Rabilloud M, El Jaffari A, Cros E, Dumontet $C$ : In vivo mechanisms of resistance to cytarabine in acute myeloid leukaemia. Br J Haematol 2002, 117:860-868.

7. Wiley JS, Jones SP, Sawyer WH: Cytosine arabinoside transport by human leukaemic cells. Eur J Canc Clin Oncol 1983, 19:1067-1074.

8. Chou TC, Arlin Z, Clarkson BD, Phillips FS: Metabolism of 1-beta-Darabinofuranosylcytosine in human leukemic cells. Cancer Res 1977, 37:3561-3570.

9. Kessel D, Hall TC, Rosenthal D: Uptake and phosphorylation of cytosine arabinoside by normal and leukemic human blood cells in vitro. Cancer Res 1969, 29:459-463.

10. Colly LP, Willemze R, Honders W, vd Hoorn F, Edelbroek PM: In vivo studies on high-dose 1-beta-D-arabinofuranosylcytosine (HDara-C) and 1-beta-Darabinofuranosyluracil (ara-U) with respect to pharmacokinetics, cell kinetics, and cytotoxicity in a rat myelocytic leukemia model (BNML). Semin Oncol 1985, 12:49-54.

11. Furth JJ, Cohen SS: Inhibition of mammalian DNA polymerase by the 5 -triphosphate of 1-beta-d-arabinofuranosylcytosine and the $5^{\prime}$-triphosphate of 9-beta-d-arabinofuranoxyladenine. Cancer Res 1968, 28:2061-2067. 
12. Graham FL, Whitmore GF: Studies in mouse L-cells on the incorporation of 1-beta-D-arabinofuranosylcytosine into DNA and on inhibition of DNA polymerase by 1-beta-D-arabinofuranosylcytosine $5^{\prime}$-triphosphate. Cancer Res 1970, 30:2636-2644.

13. Jamieson GP, Finch LR, Snook M, Wiley JS: Degradation of 1-beta-Darabinofuranosylcytosine 5 '-triphosphate in human leukemic myeloblasts and lymphoblasts. Cancer Res 1987, 47:3130-3135.

14. Galmarini CM, Graham K, Thomas X, Calvo F, Rousselot P, El Jafaari A, Cros E,

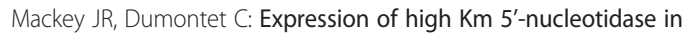
leukemic blasts is an independent prognostic factor in adults with acute myeloid leukemia. Blood 2001, 98:1922-1926.

15. Coleman CN, Stoller RG, Drake JC, Chabner BA: Deoxycytidine kinase: properties of the enzyme from human leukemic granulocytes. Blood 1975 46:791-803

16. Cory JG, Chiba P: Combination chemotherapy directed at the components of nucleoside diphosphate reductase. Pharmacol Ther 1985, 29:111-127.

17. Meuth M, Green $\mathrm{H}$ : Alterations leading to increased ribonucleotide reductase in cells selected for resistance to deoxynucleosides. Cell 1974, 3:367-374.

18. Smid K, Bergman AM, Eijk PP, Veerman G, van Haperen WW, van den ljssel P, Ylstra B, Peters GJ: Micro-array analysis of resistance for gemcitabine results in increased expression of ribonucleotide reductase subunits. Nucleosides Nucleotides Nucleic Acids 2006, 25:1001-1007.

19. Shewach DS, Reynolds KK, Hertel L: Nucleotide specificity of human deoxycytidine kinase. Mol Pharmacol 1992, 42:518-524.

20. Tang J, Xie X, Zhang X, Qiao X, Jiang S, Shi W, Shao Y, Zhou X: Long term cultured HL-60 cells are intrinsically resistant to Ara-C through high CDA activity. Front Biosci (Landmark Ed) 2012, 17:569-574.

21. Tomikawa A, Yamaguchi T, Kawaguchi T, Shudo K, Saneyoshi M: Chiral influences of feedback inhibition with dCTP on murine deoxycytidine kinase. Nucleic Acids Symp Ser 1997, 37:181-182.

22. Cai J, Damaraju VL, Groulx N, Mowles D, Peng Y, Robins MJ, Cass CE, Gros P: Two distinct molecular mechanisms underlying cytarabine resistance in human leukemic cells. Cancer Res 2008, 68:2349-2357.

23. Veuger MJ, Heemskerk MH, Honders MW, Willemze R, Barge RM: Functional role of alternatively spliced deoxycytidine kinase in sensitivity to cytarabine of acute myeloid leukemic cells. Blood 2002, 99:1373-1380.

24. Veuger MJ, Honders MW, Spoelder HE, Willemze R, Barge RM: Inactivation of deoxycytidine kinase and overexpression of P-glycoprotein in AraC and daunorubicin double resistant leukemic cell lines. Leuk Res 2003, 27:445-453.

25. Falk IJ, Fyrberg A, Paul E, Nahi H, Hermanson M, Rosenquist R, Höglund M, Palmqvist L, Stockelberg D, Wei Y, Gréen H, Lotfi K: Decreased survival in normal karyotype AML with single-nucleotide polymorphisms in genes encoding the AraC metabolizing enzymes cytidine deaminase and 5'-nucleotidase. Am J Hematol 2013, 88:1001-1006.

26. Mahlknecht U, Dransfeld CL, Bulut N, Kramer M, Thiede C, Ehninger G, Schaich M: SNP analyses in cytarabine metabolizing enzymes in AML patients and their impact on treatment response and patient survival: identification of CDA SNP C-451T as an independent prognostic parameter for survival. Leukemia 2009, 23:1929-1932.

27. Mitra AK, Crews KR, Pounds S, Cao X, Feldberg T, Ghodke Y, Gandhi V, Plunkett W, Dolan ME, Hartford C, Raimondi S, Campana D, Downing J, Rubnitz JE, Ribeiro RC, Lamba JK: Genetic variants in cytosolic 5'-nucleotidase II are associated with its expression and cytarabine sensitivity in HapMap cell lines and in patients with acute myeloid leukemia. J Pharmacol Exp Ther 2011, 339:9-23.

28. Fitzgerald SM, Goyal RK, Osborne WR, Roy JD, Wilson JW, Ferrell RE: Identification of functional single nucleotide polymorphism haplotypes in the cytidine deaminase promoter. Hum Genet 2006, 119:276-283.

29. Ueno H, Kiyosawa K, Kaniwa N: Pharmacogenomics of gemcitabine: can genetic studies lead to tailor-made therapy? Br J Cancer 2007, 97:145-151.

30. Gamazon ER, Lamba JK, Pounds S, Stark AL, Wheeler HE, Cao X, Im HK, Mitra AK, Rubnitz JE, Ribeiro RC, Raimondi S, Campana D, Crews KR, Wong SS, Welsh M, Hulur I, Gorsic L, Hartford CM, Zhang W, Cox NJ, Dolan ME: Comprehensive genetic analysis of cytarabine sensitivity in a cell-based model identifies polymorphisms associated with outcome in AML patients. Blood 2013, 121:4366-4376.

31. Kim Kl, Huh IS, Kim IW, Park T, Ahn KS, Yoon SS, Yoon JH, Oh JM: Combined interaction of multi-locus genetic polymorphisms in cytarabine arabinoside metabolic pathway on clinical outcomes in adult acute myeloid leukaemia (AML) patients. Eur J Cancer 2013, 49:403-410.

32. Mahfouz RZ, Jankowska A, Ebrahem Q, Gu X, Visconte V, Tabarroki A, Terse P, Covey J, Chan K, Ling Y, Engelke KJ, Sekeres MA, Tiu R, Maciejewski J, Radivoyevitch T, Saunthararajah Y: Increased CDA expression/activity in males contributes to decreased cytidine analog half-life and likely contributes to worse outcomes with 5-azacytidine or decitabine therapy. Clin Cancer Res 2013, 19:938-948.

33. Xu PP, Chen BA, Feng JF, Cheng L, Xia GH, Li YF, Qian J, Ding JH, Lu ZH, Wang XM, Xu K, Schultz M: Association of polymorphisms of cytosine arabinoside-metabolizing enzyme gene with therapeutic efficacy for acute myeloid leukemia. Chin Med J (Engl) 2012, 125:2137-2143.

34. Zeng $H, Y u H$, Lu L, Jain D, Kidd MS, Saif MW, Chanock SJ, Hartge P, PanScan Consortium, Risch HA: Genetic effects and modifiers of radiotherapy and chemotherapy on survival in pancreatic cancer. Pancreas 2011, 40:657-663.

35. Li L, Schaid DJ, Fridley BL, Kalari KR, Jenkins GD, Abo RP, Batzler A, Moon I, Pelleymounter L, Eckloff BW, Wieben ED, Sun Z, Yang P, Wang L: Gemcitabine metabolic pathway genetic polymorphisms and response in patients with non-small cell lung cancer. Pharmacogenet Genom 2012, 22:105-116.

36. Flach J, Dicker F, Schnittger S, Schindela S, Kohlmann A, Haferlach T, Kern W, Haferlach C: An accumulation of cytogenetic and molecular genetic events characterizes the progression from MDS to secondary AML: an analysis of 38 paired samples analyzed by cytogenetics, molecular mutation analysis and SNP microarray profiling. Leukemia 2011, 25:713-718.

37. Foran JM: New prognostic markers in acute myeloid leukemia: perspective from the clinic. Hematology Am Soc Hematol Educ Program 2010, 2010:47-55.

38. Prébet T, Boissel N, Reutenauer $S$, Thomas X, Delaunay J, Cahn JY, Pigneux A, Quesnel B, Witz F, Thépot S, Ugo V, Terre C, Recher C, Tavernier E, Hunault M, Esterni B, Castaigne S, Guilhot F, Dombret H, Vey N, Acute Leukemia French Association; Groupe Ouest-Est des leucémies et autres maladies du sang (GOELAMS); Core Binding Factor Acute Myeloid Leukemia (CBF AML) intergroup: Acute myeloid leukemia with translocation $(8 ; 21)$ or inversion (16) in elderly patients treated with conventional chemotherapy: a collaborative study of the French CBF-AML intergroup. J Clin Oncol 2009, 27:4747-4753.

39. Baralle M, Pastor T, Bussani E, Pagani F: Influence of Friedreich ataxia GAA noncoding repeat expansions on pre-mRNA processing. Am J Hum Genet 2008, 83:77-88.

40. Buratti E, Brindisi A, Pagani F, Baralle FE: Nuclear factor TDP-43 binds to the polymorphic TG repeats in CFTR intron 8 and causes skipping of exon 9: a functional link with disease penetrance. Am J Hum Genet 2004, 74:1322-1325

41. Grabczyk E, Usdin K: The GAA*TTC triplet repeat expanded in Friedreich's ataxia impedes transcription elongation by T7 RNA polymerase in a length and supercoil dependent manner. Nucleic Acids Res 2000, 28:2815-2822

42. Yamauchi $T$, Negoro E, Kishi S, Takagi K, Yoshida A, Urasaki Y, Iwasaki H, Ueda T: Intracellular cytarabine triphosphate production correlates to deoxycytidine kinase/cytosolic 5'-nucleotidase II expression ratio in primary acute myeloid leukemia cells. Biochem Pharmacol 2009, 77:1780-1786.

43. Hubeek I, Stam RW, Peters GJ, Broekhuizen R, Meijerink JP, van Wering ER, Gibson BE, Creutzig U, Zwaan CM, Cloos J, Kuik DJ, Pieters R, Kaspers GJ: The human equilibrative nucleoside transporter 1 mediates in vitro cytarabine sensitivity in childhood acute myeloid leukaemia. $\mathrm{Br} J$ Cancer 2005, 93:1388-1394.

44. Jin G, Matsushita H, Asai S, Tsukamoto H, Ono R, Nosaka T, Yahata T, Takahashi S, Miyachi H: FLT3-ITD induces ara-C resistance in myeloid leukemic cells through the repression of the ENT1 expression. Biochem Biophys Res Commun 2009, 390:1001-1006.

45. Hubeek I, Peters GJ, Broekhuizen AJ, Talianidis I, van Meeteren AY S, van Wering ER, Gibson B, Creutzig U, Kaspers GJ: Immunocytochemical detection of deoxycytidine kinase in pediatric malignancies in relation to in vitro cytarabine sensitivity. Nucleosides Nucleotides Nucleic Acids 2004 23:1351-1356.

46. Song JH, Kim SH, Kweon SH, Lee TH, Kim HJ, Kim HJ, Kim TS: Defective expression of deoxycytidine kinase in cytarabine-resistant acute myeloid leukemiacells. Int J Oncol 2009, 34:1165-1171.

47. Galmarini CM, Thomas X, Graham K, El Jafaari A, Cros E, Jordheim L, Mackey JR, Dumontet $\mathrm{C}$ : Deoxycytidine kinase and $\mathrm{CN}-\mathrm{Il}$ nucleotidase expression in blast 
cells predict survival in acute myeloid leukaemia patients treated with cytarabine. Br J Haematol 2003, 122:53-60.

48. Veuger MJ, Honders MW, Willemze R, Barge RM: Deoxycytidine kinase expression and activity in patients with resistant versus sensitive acute myeloid leukemia. Eur J Haematol 2002, 69:171-178.

49. Veuger MJ, Honders MW, Landegent JE, Willemze R, Barge RM: High incidence of alternatively spliced forms of deoxycytidine kinase in patients with resistant acute myeloid leukemia. Blood 2000, 96:1517-1524

50. Abraham A, Varatharajan S, Abbas S, Zhang W, Shaji RV, Ahmed R, Abraham A, George B, Srivastava A, Chandy M, Mathews V, Balasubramanian P: Cytidine deaminase genetic variants influence RNA expression and cytarabine cytotoxicity in acute myeloid leukemia. Pharmacogenomics 2012, 13:269-282.

51. Cao X, Mitra AK, Pounds S, Crews KR, Gandhi V, Plunkett W, Dolan ME, Hartford C, Raimondi S, Campana D, Downing J, Rubnitz JE, Ribeiro RC, Lamba JK: RRM1 and RRM2 pharmacogenetics: association with phenotypes in HapMap cell lines and acute myeloid leukemia patients. Pharmacogenomics 2013, 14:1449-1466.

52. Galmarini CM, Cros E, Thomas X, Jordheim L, Dumontet C: The prognostic value of $\mathrm{cN}-\mathrm{II}$ and $\mathrm{cN}-\mathrm{III}$ enzymes in adult acute myeloid leukemia. Haematologica 2005, 90:1699-1701.

53. Falk IJ, Willander K, Chaireti R, Lund J, Nahi H, Hermanson M, Gréen H, Lotfi K, Söderkvist P: TP53 mutations and MDM2SNP309 identify subgroups of AML patients with impaired outcome. Eur J Haematol 2014, 23.doi:10.1111/ejh.12438

54. Zhuo W, Zhang L, Wang Y, Zhu B, Chen Z: CYP1A1 Mspl polymorphism and acute myeloid leukemia risk: meta-analyses based on 5018 subject. J Exp Clin Cancer Res 2012, 31:62-71.

55. Fiegl M, Unterhalt M, Kern W, Braess J, Spiekermann K, Staib P, Grüneisen A, Wörmann B, Schöndube D, Serve H, Reichle A, Hentrich M, Schiel X, Sauerland C, Heinecke A, Rieger C, Beelen D, Berdel WE, Büchner T, Hiddemann W, German AML Cooperative Group (AMLCG):

Chemomodulation of sequential high-dose cytarabine by fludarabine in relapsed or refractory acute myeloid leukemia: a randomized trial of the AMLCG. Leukemia 2014, 28:1001-1007.

56. Mehta DR, Foon KA, Redner RL, Raptis A, Agha M, Hou JZ, Duggal S, Luong TM, Schlesselman JJ, Boyiadzis M: Fludarabine and cytarabine in patients with acute myeloid leukemia refractory to two different courses of front-line chemotherapy. Leuk Res 2011, 35:885-888.

doi:10.1186/s13046-014-0090-9

Cite this article as: Wan et al: SLC29A1 single nucleotide polymorphisms as independent prognostic predictors for survival of patients with acute myeloid leukemia: an in vitro study. Journal of Experimental \& Clinical Cancer Research 2014 33:90.

\section{Submit your next manuscript to BioMed Central and take full advantage of:}

- Convenient online submission

- Thorough peer review

- No space constraints or color figure charges

- Immediate publication on acceptance

- Inclusion in PubMed, CAS, Scopus and Google Scholar

- Research which is freely available for redistribution 